\title{
Not eating like a pig: European wild boar wash their food
}

Volker Sommer (1)

Adriana Lowe (1)

Tanja Dietrich (2)

(1) Department of Anthropology, University College London, London, United Kingdom

(2) Basle Zoo, Basle, Switzerland

Words 2079

Corresponding author:

Volker Sommer

Department of Anthropology

University College London

14 Taviton Street

London WC1H 0BW

United Kingdom

Tel. +44(0)20 76798838

Fax. +44(0)20 76798632

E-Mail v.sommer@ucl.ac.uk 


\section{Abstract}

Carrying food to water and either dunking or manipulating it before consumption has been observed in various taxa such as birds, racoons and primates. Some animals seem to be simply moistening their food. However, true washing aims to remove unpleasant surface substrates such as grit and sand and requires a distinction between items that do and do not need cleaning as well as a deliberate transport of food to a water source. We provide first evidence for food washing in suids, based on an incidental observation with simple follow-up experiments on European wild boar (Sus scrofa) kept at Basle Zoo, Switzerland. Here, all adult pigs of a newly formed group carried apple halves soiled with sand to the edge of a creek running through their enclosure where they put the fruits in the water and pushed them to and fro with their snouts before eating. Pigs are known to be capable of individual problem solving. However, given that the behaviour was not observed at the animals' previous locations, social learning appears to have been involved when this technique developed at Basle Zoo.

\section{Introduction}

Animals of several species carry food to water and either dunk or manipulate it (e.g., birds, Morand-Ferron et al. 2004; racoons, Lyall-Watson 2008; monkeys, Kawai 1965, Visalberghi \& Fragaszy 1990, Nakamichi et al. 1998; great apes, Alltritz et al. 2013). Often described as "washing", this presumably removes unpleasant surface substrates such as grit and sand that may wear down teeth or beaks (Watanabe 1994).

However, experiments suggest that washing may not always be the primary function of this behaviour. For example, Carib grackles seem to be moistening, rather than washing, their food (Morand-Ferron et al. 2004) while racoon "washing" may actually be a natural 
riverbank foraging technique, unrelated to cleaning (Lyall-Watson 2008). Unambiguous washing involves transporting food deliberately to a water source and a distinction between items that do and do not need cleaning (Kawai 1965, Visalberghi \& Fragaszy 1990, Nakamichi et al. 1998, Alltritz et al. 2013).

Of interest in terms of cognition are the mechanisms related to washing, such as whether it is individually acquired (Visalberghi \& Fragaszy 1990, Alltritz et al. 2013), e.g., through trial and error or insight or if it is based on social transmission (Kawai 1965) via, e.g., stimulus enhancement, emulation or imitation.

As the pig (Sus scrofa) is capable of a range of learning and memory tasks (review in Gieling et al. 2011), one might expect that these ungulates also have the capacity to exhibit food washing. However, as far as we are aware, this has not yet been reported. Here we provide first evidence for food washing in suids.

\section{Materials and methods}

Our account is based on an incidental observation with simple follow-up experiments on European wild boar kept at Basle Zoo, Switzerland.

The three adult study subjects arrived at Basle on 21Mar13 where they quickly formed a social group: (a) female 133101, born 05Apr12 at Tierpark Langenberg, $\mathrm{CH}$; (b) female 133102, born 23Mar12 at Tierpark Lange Erlen, CH; (c) male 133103 - sibling to (b) born 23Mar12 at Tierpark Lange Erlen, $\mathrm{CH}$. Piglets of unknown sex were born to the females after arrival at Basle on 23Apr13 and 04Aug13.

The animals' enclosure had a natural creek passing through it in which the pigs were first observed washing food just over two months after arrival at the zoo. A layer of 
fresh sand had been laid down in some parts of the enclosure prior to introducing the animals.

Observation 1 (15May13, 11:00). The newly arrived pigs were being exhibited to representatives of the local press and provided with halved apples to encourage activity for the benefit of the visitors. The sand in the enclosure stuck to the cut side of some of the fruit.

Observation 2 (29Aug13, 15:00-15:30). The pigs were deprived of food in the morning to heighten their interest in apples later on. They were then provided with halved apples in the afternoon. These were deliberately thrown onto the sandy parts of the enclosure and some were prepared by being rubbed with sand.

Observation 3 (19Sep13, 15:00-15:30). The pigs were again deprived of food in the morning and provided with halved apples in the afternoon. The fruit had been rubbed with sand prior to being thrown. Maize cobs, likewise rubbed with sand, were also provided.

\section{Results}

In each instance where apples were provided, all adult pigs carried halves to the edge of the creek where they put them in the water and pushed them to and fro with their snouts. When the apples were more or less free of sand, after up to $30 \mathrm{sec}$ of washing, they were eaten. In the cases where the pigs had not been fed in the morning, they ate some halves without washing before processing subsequent pieces in the water. After this, they ate some apples uncleaned while washing others before consuming them. The pigs also bit several already washed fruits into smaller chunks and rewashed them, repeatedly rolling the pieces in the water. 
When maize cobs were provided, these were clearly preferred over apple halves and eaten without washing.

The piglets did not carry the apples to the water. However, they did carry them around in the enclosure, and occasionally rubbed them with their snouts, perhaps attempting to clean off sand before eating. On one occasion, they found an apple half already lying at the water's edge that they pushed around with their snouts, in a similar way to the adults, before eating.

Keepers at the pigs' previous locations reported no such behaviour. In Tierpark Langenberg, they accessed water via a small fountain and automatic drinker water troughs, while a large water source was lacking. However, in Tierpark Lange Erlen, a shallow creek passed through the enclosure in which the pigs often lied down to rest. Pigs often chose to eat food while standing in the water but targeted washing was not observed. Thus, the pigs appeared to have developed this behaviour at Basle Zoo.

\section{Discussion}

The cleaning of sandy apples by European wild boar at the Basle Zoo matches other descriptions of washing as it involves carrying certain soiled food items to water and removing surface substrates prior to eating (Kawai 1965, Visalberghi \& Fragaszy 1990).

The behaviour appears deliberate in that the adult pigs all rolled the fruit repeatedly in the water with their snouts. However, some soiled apples were eaten uncleaned. Although it appears likely, it is not clear whether the pigs discriminated between sandy and less sandy apples when they washed certain items. This could have been because by tasting the apples, the pigs developed a dislike for the sand and only began to wash them afterwards. Experiments with capuchins report the monkeys similarly tasting sandy food items first, before attempting to remove the sand (Visalberghi \& Fragaszy 1990). 
The keeper's interpretation is that the pigs' hunger in cases 2 and 3 induced them to eat some apples immediately before resuming washing behaviour, as this would have delayed consumption. Similarly, according to the keeper, apples are not a preferred food and more desirable items such as maize are perhaps too tempting to waste time with washing. Delaying gratification is a difficult skill, which typically defeats highly intelligent organisms such as chimpanzees and human infants (Morales et al. 2005, Tomasello \& Call 1997), and is perhaps likewise beyond the scope of the pigs.

It may also be that desirable foods are more liable to be competed over. Carib grackles in larger groups where competition is higher, are less likely to dunk food in water (Morand-Ferran et al. 2004). Similarly, when macaques carry grass roots to water for washing, the behaviour is limited to middle and high ranking individuals (Nakamichi et al. 1998). This likely reflects the chance of high quality food being stolen if it is not eaten immediately.

Keepers at Basle Zoo have also reported anecdotes of pigs immersing whole dead chickens in water that were supplied to them. They suggest that, rather than true food washing, this may well be a case of dunking to moisten the dry feathers.

The properties of the fruit itself may also explain why it alone has been observed being washed. The apples had freshly cut sides, which would gather more sand than dry food and are ideally sized to be carried individually to the water. Maize, on the other hand, which was not washed, was typically shaved off the cob by the pigs, perhaps making it unsuitable for carrying or washing as the small pieces would be much harder to manipulate and could be lost in the water. The smooth, dry sides of maize pieces also means that far less sand became attached in the first place.

In terms of learning the behaviour, it is not clear whether the adult pigs came to wash their food individually, or if some social transmission was involved. The behaviour of the piglets suggests that a form of stimulus enhancement could be at play, a mechanism 
known to be in active in pigs when learning foraging techniques (Oostingdjer et al. 2011).

The fact that this behaviour was not observed at the pigs' previous locations suggests that a degree of social learning was perhaps at play. It seems likely that were they all capable independently of learning to wash food, they would have been observed doing it before being brought together.

That pigs at one of the previous locations, Tierpark Lange Erlen, often ate standing in water could indicate a group tradition (Perry \& Manson 2003). If this was also linked to washing, then the method varied between the two sites, i.e. washing at the water's edge versus washing while standing in the water.

Evidently, food washing is not a particularly complicated behaviour to acquire (Visalberghi 1990), as animals of several species are well capable of learning to wash on their own in experimental settings (Alltritz et al. 2013). The natural foraging technique of pigs involves using the snout to rummage for food items-(Pacioni 1986), hence the long dextrous snout is well capable of manipulating small objects. Thus, rolling apples with the snout reflects a familiar technique. Pigs therefore would not need to learn additional skills to wash apples, perhaps making innovation more likely as it simplifies the process.

In terms of abilities, pigs are capable of individual problem solving (Gieling et al. 2011). However, given that the behaviour was not observed at the pigs' previous locations, social learning such as exploiting the foraging knowledge of others (ibid.) appears to have been involved when this technique developed at Basle Zoo.

\section{References}


Allritz M, Tennie C, Call J (2013) Food washing behaviour and placer mining in captive great apes. Primates 54:361-370

Gieling ET, Nordquist RE, van der Staay FJ (2011) Assessing learning and memory in pigs. Animal Cogn 14:151-173

Kawai M (1965) Newly-acquired pre-cultural behavior of the natural troop of Japanese monkeys on Koshima Islet. Primates 6:1-30

Morales M, Mundy P, Crowson M, Neal R, Delgado C (2005) Individual differences in infant attention skills, joint attention, and emotion regulation behavior. Int J Behav Devel 29:259-63

Morand-Ferron J, Lefbvre L, Reader SM, Sol D, Elvin S (2004) Dunking behaviour in Carib grackles. Animal Behav 68:1267-1274

Nakamichi M, Kato E, Kojima Y, Itoigawa N (1998) Carrying and washing of grass roots by free-ranging Japanese macaques at Katsuyama. Folia Primatol 69:35-40

Oostindjer M, Bolhuis JE, Medl M, Held S (2011) Learning how to eat like a pig: effectiveness of mechanisms for vertical social learning in piglets. Anim Behav 82:503511

Pacioni G (1986) Truffle hunting in Italy. Bull Br Mycol Soc 20:50-51

Perry S, Manson JH (2003) Traditions in monkeys. Evol Anthr 12:71-81

Tomasello M, Call J (1997) Primate cognition. Oxford, Oxford University Press Visalberghi E, Fragaszy DM (1990) Food-washing behaviour in tufted capuchin monkeys, Cebus apella, and crabeating macaques, Macaca fascicularis. Animal Behav 40:829-836 
Watanabe K (1994) Precultural behavior of Japanese macaques: longitudinal studies of the Koshima troops. In: Gardner RA, Gardner BT, Chiarelli B, Plooij FC (eds). The ethological roots of culture. Kluwer, Dordrecht, pp 81-91 